\title{
Replication of Bone Marrow Differentiation Niche: Comparative Evaluation of Different Three-Dimensional Matrices
}

\author{
Meghan J. Cuddihy, Yichun Wang, Charles Machi, Joong Hwan Bahng, \\ and Nicholas A. Kotov*
}

The interactions between hematopoietic stem cells (HSCs) and the bone marrow niche are very complex and poorly understood. ${ }^{[1,2]}$ Bone marrow stroma, the tissue surrounding hematopoietic tissue, is composed of a variety of cell types and extracellular matrix (ECM) molecules. ${ }^{[3-7]}$ HSCs interact with these cell types directly through cell-cell contacts or indirectly through secreted growth factors or ECM. Blood and bone marrow diseases, such as chronic myelogenous leukemia, acute myelogenous leukemia, and bone marrow failure syndromes, are characterized by disordered development or production of hematopoietic cells in the bone marrow. ${ }^{[8,9]}$ In fact, some of these HSC diseases are thought to be influenced by interactions with stromal cells. ${ }^{[10]}$ Exploration of the interactions between HSCs, surrounding stromal cells, and ECM is necessary for better understanding of these diseases.

Traditional in-vitro models of the HSC niche are dependent on HSC culture on 2D surfaces. In order to provide niche signals to the HSCs, they are cultured either on stromal cells, ${ }^{[11,12]}$ in media supplemented with high concentrations of growth factors, ${ }^{[13,14]}$ or both. Although the $2 \mathrm{D}$ models allow for the maintenance and expansion of HSCs, they lack the dimensionality and ECM components of the HSC niche. ${ }^{[15]}$ With this in mind, 3D models of the bone marrow niche, primarily designed for HSC expansion, were developed.

Dr. M. J. Cuddihy, C. Machi, Prof. N. A. Kotov Department of Chemical Engineering University of Michigan

3074 H. H. Dow Building, 2300 Hayward Street

Ann Arbor, MI 48109, USA

E-mail: kotov@umich.edu

Y. Wang, J. H. Bahng, Prof. N. A. Kotov Department of Biomedical Engineering 3074 H. H. Dow Building, 2300 Hayward Street, Ann Arbor, MI 48109, USA

Prof. N. A. Kotov

Department of Material Sciences and Engineering

Biointerface Institute

University of Michigan

3074 H. H. Dow Building,

2300 Hayward Street, Ann Arbor, MI 48109, USA

DOI: $10.1002 / \mathrm{smll} .201202133$
These models ranged from porous natural ${ }^{[16]}$ and scaffoldfree co-cultures ${ }^{[17]}$ to nanofiber scaffolds ${ }^{[18,19]}$ and synthetic polymers. ${ }^{[20-22]}$ Most recently, De Barros et al. ${ }^{[17]}$ developed a complex mixed multicellular spheroid in vitro model with human BMSC undifferentiated or induced for one week into osteoblasts. Both types of BMSC self-assembled in a 3D spheroid effectively contact with hematopoietic progenitor cells. Cook et al. ${ }^{[23]}$ describe a novel high-throughput 3D coculture system where murine-derived HSC can be cocultured with mesenchymal stem/stromal cells in 3D 'micromarrows', which supported the expansion of approximately twice as many HSC candidates as the $2 \mathrm{D}$ controls. Leisten et al. proposed a collagen-based 3D model for hematopoietic stem and progenitor cells with mesenchymal stem cells to recapitulate the main components of the bone marrow niche, and proved the collagen-based 3D model enabled progenitor cell expansion.

Although these matrices vary in features such as sizes of pore structures, material types and sources, no study has compared matrix features in the context of HSC culture. A comparison of key cell culture formats would help researchers determine what features of these matrices are necessary for mimicking the HSC niche. This is especially important for mimicking the healthy or diseased HSC niche in the context of drug testing, where the impact of a treatment may involve not only the HSCs but their interaction with stromal cells or ECM molecules. Knowledge of cell culture matrices features with regard to the HSC niche will aid researchers in better understanding of the interactions that occur in the HSC niche, and thereby better treatment options could be developed for diseases associated with the niche.

In the studies described here, we aimed to compare several matrices with distinct spatial features: Matrigel is an ECM-based nanofibrous cell-encapsulating gel; Puramatrix is a synthetic peptide-based nanofibrous cell-encapsulating gel; inverted colloidal crystal (ICC) scaffolds are synthetic polymeric hydrogels with a distinct structure that does not fully encapsulate cells; and well plates are 2D solid polystyrene surfaces that serve as controls compared to the 3D matrices.

Matrigel is composed of ECM proteins extracted from Engelbreth-Holm-Swarm mouse sarcomas. ${ }^{[24,26]}$ The gel has an advantage of being liquid at $4{ }^{\circ} \mathrm{C}$ and gelling at $37{ }^{\circ} \mathrm{C}$. With this property, Matrigel can be mixed with cells, proteins, or other desired culture components at the low temperature, 
and it will polymerize into a gel after plating at room temperature. Matrigel contains several growth factors, including TGF-beta, epidermal growth factor, and fibroblast growth factor, so it can be a source of soluble signals that may be useful for certain applications. ${ }^{[26-29]}$ Since Matrigel is composed of in-vivo sources, cells can digest and restructure the matrix. ${ }^{[30]}$ This feature is useful for through-tissue migration studies, ${ }^{[31]}$ but can be hindering in tissue engineering or modeling applications where matrix digestion disrupts the 3D structure. As well, the murine source of Matrigel introduces the potential of viral contamination.

The second gel we examined was Puramatrix, which is a peptide gel that self-assembles when exposed to the electrolytes in cell culture media. ${ }^{[32]}$ The gels promote cell attachment, ${ }^{[33]}$ and can be plated in concentrations ranging from $0.1-1 \%$. Both Matrigel and Puramatrix are nanofibrous gels, which can be used to create 3D cell cultures by encapsulating the cells. However, Puramatrix is fairly inert comparing to Matrigel, because Matrigel contains exogenous growth factors and a heterogeneous fibrous makeup, while Puramatrix is composed of a synthetic protein but no growth factors. These encapsulating gels could be advantageous to HSC culture in that they allow for intimate cell-ECM interaction; however, the cell-cell interaction could be limited due to encapsulation.

We also looked at a 3D hydrogel matrix that allows for cell attachment but is not an encapsulating gel. Recently, these matrices, called inverted colloidal crystal (ICC) scaffolds, were utilized to design a 3D bone marrow analog. ${ }^{[34]}$ ICC scaffolds are hydrogel matrices with uniformly shaped spherical cavities arranged in a hexagonal array where each cavity is connected to twelve adjacent cavities. ${ }^{[35-42]}$ In a recent study, ${ }^{[34]}$ the bone marrow analog utilized a transparent acrylamide hydrogel with $70 \%$ water content, coated with clay nanocomposite to allow for cell attachment and to mimic the mineralized surface of bone. CD $34^{+}$cells, hematopoietic progenitor cells, were expanded within scaffolds with the support of growth factors and bone marrow aspirates, and the $\mathrm{CD}_{3} 4^{+}$cells were then differentiated into functioning B-cells. The results showed that the $3 \mathrm{D}$ interactions are necessary for control of $\mathrm{CD}^{+} 4^{+}$cell cultures and purposeful ex-vivo bone marrow engineering. The ICC scaffolds demonstrated some intrinsic advantages with the stromal-CD34 ${ }^{+}$ cell co-culture. The geometry of closely-packed spherical cavities provided 3D interactions between the stromal cells and stem cells. Physically, the stem cells could contact stromal cells from multiple directions, especially when compared to the unidirectional interactions on 2D well plates. As well, soluble factors are released in all directions from the attached stromal cells, eliminating the steep concentration gradient that is seen in 2D. The interconnectivity also played a big role in stromal-stem cell interactions. As CD34+ cells are not attachment-based, they were free to migrate throughout the scaffold. This is unique to the ICC scaffolds when compared to encapsulation-based 3D matrices such as Matrigel.

We also performed parallel cultures in traditional 2D tissue cultured polystyrene. A direct comparison between these cell culture formats has not been performed systematically in the context of the HSC niche. In addition to dimensionality and feature scale, it is important to note the differences in cell-cell contacts in each of these formats. In $2 \mathrm{D}$ culture, the as $\mathrm{CD} 34^{+}$cells are plated on top of stromal cells so the two cell types are in direct contact. In order to provide a true $3 \mathrm{D}$ structure to the Matrigel and Puramatrix culture, one must encapsulate the cell cultures in the gel by mixing the gel and cells before plating. With cell encapsulation, cells are surrounded and separated by matrix, limiting cell-cell contact. For cells to have cell-cell contact, they must digest the matrix and migrate to one another. As ICC scaffolds have a porous $3 \mathrm{D}$ structure, they can be seeded directly onto the matrix, allowing for them to contact not only the matrix but also each other. Thus, with these three matrices we can compare $2 \mathrm{D}$ and $3 \mathrm{D}$ matrices, as well as those with and without cell-cell contact. In vivo, bone marrow is a complex 3D tissue with extensive cell-cell contacts. Replication of its essential functions in vitro inevitably forces the selection of only a subset of these interactions which determines the importance of a cell culture format.

In all culture formats, stromal-free cultures show a sparse number of $\mathrm{CD}_{3} 4^{+}$cells and their progeny (Figure 1A,D,G). These cultures showed little, if any, expansion. All other images in Figure 1 feature cultures that included stromal cells. In 2D cultures (Figure 1B,C) stromal cells lay flat and $\mathrm{CD}_{3}{ }^{+}$cells and their progeny are smaller and remain round on top of the stromal cells. Stromal cells in Matrigel cultures (Figure 1E,F) are rounded and isolated from the hematopoietic cells due to encapsulation. Some stromal cells have migrated to the bottom of the plate and lay flat (Figure 1F). Puramatrix cultures showed similar morphologies. In ICC cultures, stromal cells are difficult to see because they conformably adhere to the matrix and the hematopoietic cells cluster within cavities. In all cultures, cells appeared mostly viable (Figure 1J-L).

The number of cells that could be extracted from each culture type at days 7 and 14 were quantified using a hematocytometer (Figure 2A). These cells included both stromal cells, CD $34^{+}$cells, and their progeny. In all matrices the numbers of cells in stromal cell-free culture were very low, indicating that cells did not replicate. The cells extracted from 2D surfaces displayed little growth at day 7 but had expanded by day 14. Conversely, cells grown in Matrigel expanded significantly at day 7 but had decreased by day 14. ICC scaffold cultures displayed consistent cell numbers over the two weeks. The amount of expansion, represented as the number of cells extracted divided by the number of cells initially seeded in the cultures, is displayed in Table $\mathbf{1 .}$

Enumeration of cells that were $\mathrm{CD} 34^{+} / \mathrm{lin}^{-}$was performed by flow cytometry. In most matrices, stromal cell-free cultures displayed a higher percentage of cells that were $\mathrm{CD} 34^{+} / \mathrm{lin}^{-}$ than cultures with stromal cells (Figure 2B). It is important to remember that these cultures began with $100 \% \mathrm{CD}^{+} 4^{+} / \mathrm{lin}^{-}$ cells. In the majority of co-cultures, the percentage of $\mathrm{CD}^{+} 4^{+} /$ $\mathrm{lin}^{-}$had decreased from $20 \%$ of the total number of cells (as seeded) to less than $10 \%$.

The number of $\mathrm{CD}^{4} 4^{+} / \mathrm{lin}^{-}$cells (Figure 3 ) was calculated by multiplying the data shown in Figure 2A by those in Figure 2B. None of the matrices and cell combinations significantly expanded the $\mathrm{CD}^{+} 4^{+} / \mathrm{lin}^{-}$population (Table 1 ). $2 \mathrm{D}$ co-cultures 

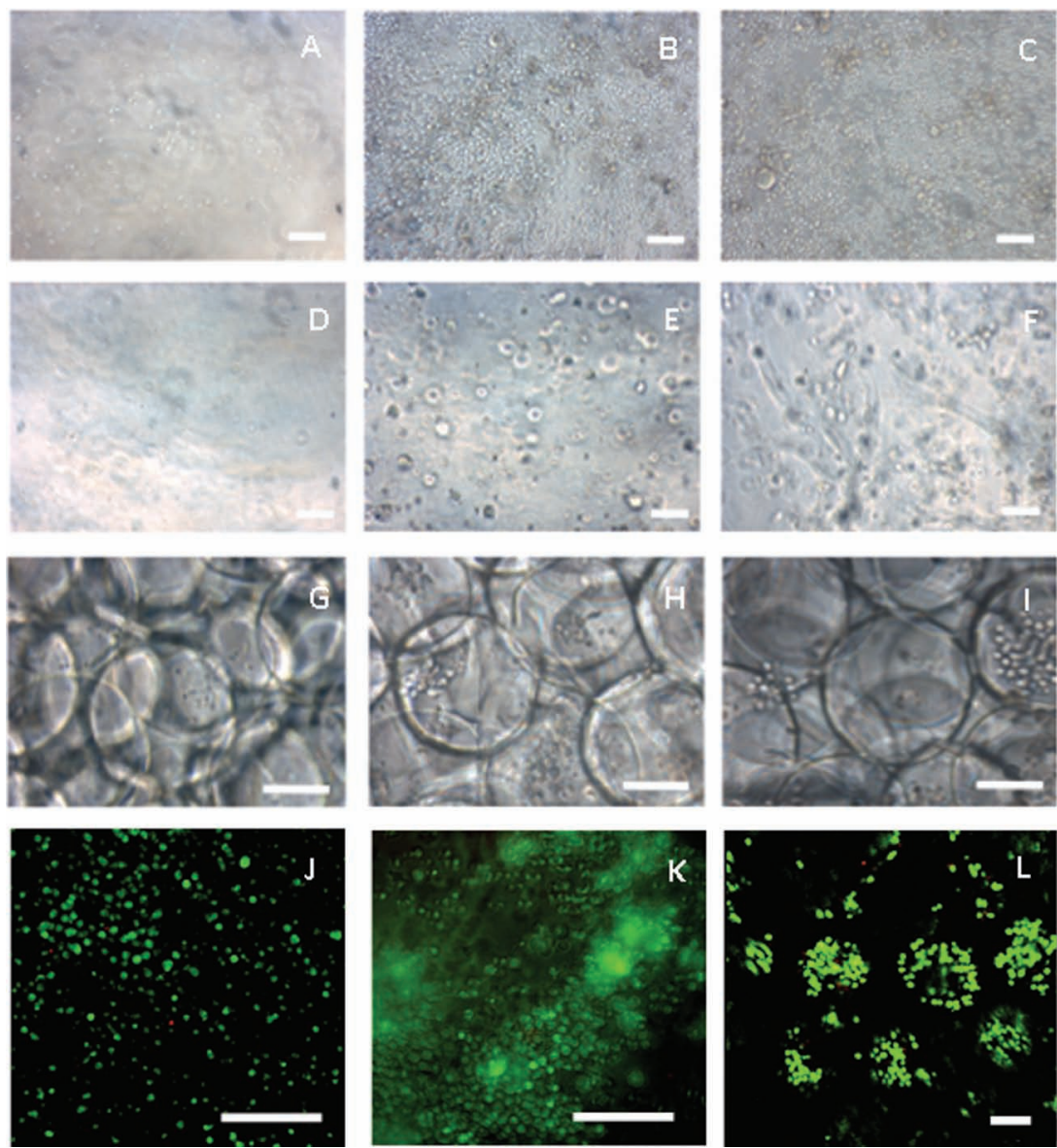

Figure 1. Representative images of matrices. (A-I) Inverted microscope images (phase contrast) of cells in matrices on day 7. (J-L) Confocal images with live/dead stain. The first row of images $(A, B, C)$ shows cells grown in $2 D$, the second row $(D, E, F)$ shows cells grown in Matrigel, and the third row $(G, H, I)$ shows cells grown in ICC scaffolds. The first column (A,D,G) displays $C D 34^{+}$cells grown alone, the second column (B,E,H) displays CD34 $/ \mathrm{hFOB} 1.19$ co-cultures, the third column (C,F,I) displays CD34 $4^{+} / \mathrm{HS}-5$ co-cultures. The fourth row, cells stained with the live/dead assay, shows cells grown in (J) 2D, (K) Matrigel, and (L) ICCs. Green cells are alive, while cells stained red are dead. Images of Puramatrix cultures are not pictured because of their similarity to Matrigel cultures. Scale bar: (A-I) $100 \mu \mathrm{m},(\mathrm{J}-\mathrm{L}) 80 \mu \mathrm{m}$.

displayed a recovery of the original number of $\mathrm{CD}^{2} 4^{+} / \mathrm{lin}^{-}$cells between 7 and 14 days. ICC scaffolds displayed a fairly consistent number of $\mathrm{CD} 34^{+} / \mathrm{lin} 1^{-}$cells from day 7 to day 14 . Matrigel, in contrast to Figure 2A, produced very few $\mathrm{CD} 34^{+} /$ $\operatorname{lin}^{-}$cells by day 7 , meaning that the expanded population seen in the first seven days was a progeny population. Puramatrix showed low numbers of $\mathrm{CD}^{+} / \mathrm{lin}^{-}$cells at day 7 , but displayed a population profile similar to Matrigel by day 14 .

ELISAs for SCF, Flt-3, and IL-6 were performed on media extracted from cultures (Figure 4). SCF and Flt-3 were found in concentrations much lower than levels used to expand HSCs. ${ }^{[18]}$ IL-6 was found in concentrations 100 times higher than Flt-3 and IL-6. Stromal cell cultures had significantly higher levels of IL-6 than cultures without stromal cells. In most cultures, HS-5 cells typically produced significantly more IL- 6 than hFOB 1.19 or stromal cell-free cultures.

We chose four cell culture formats with several different features to explore the contributions of dimensionality and cell-cell contacts in engineering an ex vivo HSC niche to achieve eventually ex-vivo replica of bone marrow. The traditional 96-well plate was a $2 \mathrm{D}$ culture that allowed for communication through direct cell-cell interactions and secreted cytokines, Matrigel and Puramatrix were 3D cultures where the matrix encapsulated the cells, allowing only for communication via secreted cytokines. ICC scaffolds represented 3D non-encapsulating cultures that allow for communication via direct contacts and secreted cytokines.

In addition to cell culture formats, we looked at several co-culture combinations. All cultures were performed without cytokines, in order to reveal the effects of cell culture format and stromal cell type. As well, an ideal model of a HSC niche should have all signals provided by cells and matrix which should be the same as those provided by cells and ECM in vivo. A stromal-cell free culture served as a control. HS-5 cells were developed from bone marrow specifically for the support of HSCs. ${ }^{[11,12]}$ HS-5 cells were shown to produce high levels $(>1000 \mathrm{pg} / \mathrm{mL})$ of growth factors IL-6, IL-8, granulocyte colonystimulating factor (G-CSF), and macrophage-inhibitory protein-1 alpha and also produced detectable levels of granulocytemacrophage-CSF (GM-CSF), macrophageCSF (M-CSF), Kit ligand (KL, also called SCF), and others. ${ }^{[11]}$ Osteoblasts are important to consider because (1) they secrete extracellular matrix and (2) they contribute to Ang1-Tie2 and transmembrane SCF signaling $[7,44,48]$ taking place at osteoblastHSC contacts. The known cellular products of the hFOB 1.19 cell line include alkaline phosphatase and osteocalcin. ${ }^{[48]}$

The chosen matrices represented a diverse array of geometries (Figure 1). 2D cultures caused the stromal cells to lay flat on the plate surface, and HSCs typically associated with the top of these cells. As CD34+ cells are not attachmentbased, the $\mathrm{CD} 34^{+}$cells rarely contact the well plate, indicating that the $\mathrm{CD}_{3} 4^{+}$cells showed affinity towards cell-cell contacts. Matrigel and Puramatrix cultures began with cells encapsulated through the matrix. After one week, it was observed that some stromal cells had migrated toward the bottom of the plate. ICC scaffolds allowed for direct 3D interactions between stromal cells and $\mathrm{CD} 34^{+}$cells. It was observed that the $\mathrm{CD}^{+} 4^{+}$cells and their progeny expanded in the cavities, forming small niches in several cavities. The geometry of the cavities where the stem cell expansion was observed (Figure 1I and L) are very similar to the niches that are seen in actual bone marrow. ${ }^{[49-51]}$ The geometry of ICC scaffolds is much like that of trabecular bone; thus, the directionality of interactions and degree of contact between stromal and stem cells is very similar in ICCs and bone marrow. 
A

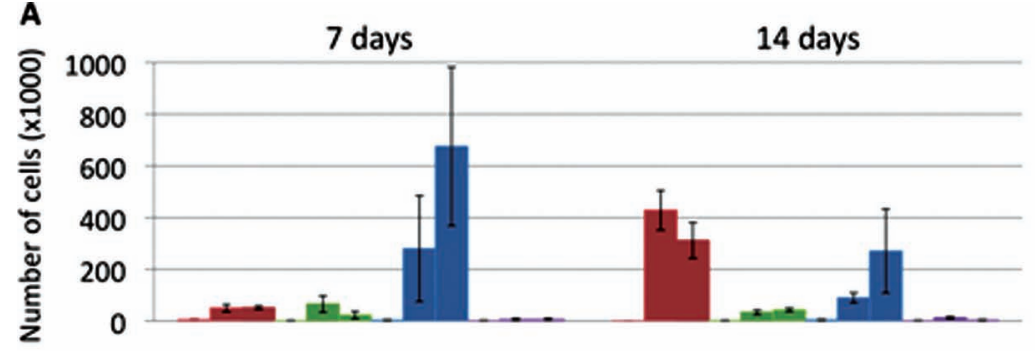

$\mathbf{B}$

C

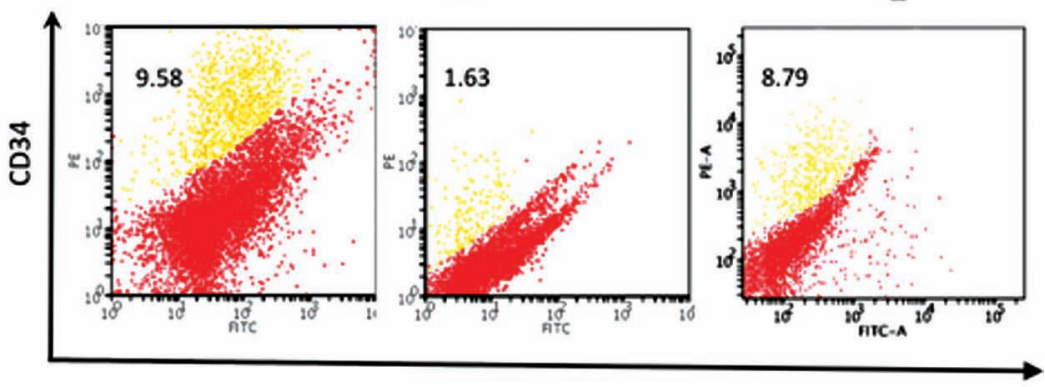

lin

Figure 2. Number and phenotype of cells extracted from cultures. (A) Number of cells extracted from culture formats on indicated days. Note that all co-cultures produced significantly $(p<0.05)$ more cells than the cultures with $C D 34^{+}$cells alone. In all instances, within the same matrix type and day, the number of cells produced by hFOB 1.19 co-cultures were not significantly different when compared to the HS- 5 cultures. (B) Percentage of cells that displayed the $\mathrm{CD} 34^{+} / \mathrm{lin}^{-}$phenotype. For each matrix type, $\mathrm{CD} 34^{+}$cells cultured alone displayed significantly $(\mathrm{p}<0.05)$ higher percentages of $\mathrm{CD}^{2} 4^{+} /$lin $^{-}$cells than co-cultures of that same matrix type and day. (C) Representative dot plots of flow cytometry data for HS-5/ $\mathrm{CD} 34^{+}$cultures in, from left to right, 2D, Matrigel, and ICC cultures at seven days. Percentages on dot plots indicate the percentange that measured $\mathrm{CD}_{3} 4^{+} / \mathrm{lin}^{-}$.

2D co-cultures showed the largest expansion of $\mathrm{CD} 34^{+} /$ $\operatorname{lin}^{-}$cells over 14 days (Figure 3); however, the total numbers of cells in these cultures are comparable to ICC and Matrigel cultures (Figure 2). This implies that 2D culture format specifically promotes expansion of $\mathrm{CD}^{+} 4^{+} / \mathrm{lin}^{-}$cells without further differentiation as can be detected by the chosen antibodies. ICC co-cultures, by comparison, show a more stable population of $\mathrm{CD} 34^{+} / \mathrm{lin}^{-}$cells, and total cells, over 14 days.

Matrigel cultures differentiated and expanded, or vice versa, over seven days. Interestingly, Puramatrix and Matrigel cultures have very similar numbers of $\mathrm{CD}^{2} 4^{+} / \mathrm{lin}^{-}$cells at 14 days for all co-cultures. The reason for the expansion and differentiation of HSCs in Matrigel may be due to the exogenous growth factors present in the matrix. As these factors were not replaced during media changes, the factors were likely used up during the culture, allowing for a recovery of $\mathrm{CD} 34^{+} /$ lin $^{-}$cell numbers during the second week for HS-5 cultures. Shown in Figure 4C, HS-5 cultures secrete high levels of IL-6. As Matrigel and Puramatrix cultures isolate cells from one another due to matrix encapsulation, it is logical that the $\mathrm{CD} 34^{+} /$ lin $^{-}$growth profiles would follow the profile of secreted factors.

We looked into three of the signals that were secreted in the media (Figure 4), and found that IL- 6 was secreted at physiologically relevant levels, particularly by HS-5 cells. Furthermore, we found that the pattern of IL-6 secretion in Figure 4C followed the pattern of $\mathrm{CD} 34^{+} / \mathrm{lin}^{-}$cell numbers in Figure 3. Thus, with the cell types used here, particularly HS-5, IL-6 is the secreted signal dominating $\mathrm{CD} 34^{+} / \mathrm{lin}^{-}$cell maintenance. It is interesting to note that although all three formats presented similar levels of IL-6, the 2D format showed the greatest expansion of $\mathrm{CD}^{2} 4^{+} / \mathrm{lin}^{-}$cells. In $2 \mathrm{D}$, there is a distinct concentration gradient from the source of soluble cytokines at the bottom of the plate to the top of the plate. Therefore, in 2D cultures the HSCs are exposed to very high concentrations of soluble cytokines. In 3D cultures, this gradient is lessened considerably due to the arrangement of stromal cells, and thus the secretion of soluble cytokines, in three dimensions.

For both Matrigel and Puramatrix cultures, $\mathrm{CD} 34^{+} / \mathrm{lin}^{-}$cells expand significantly between 7 and 14 days only in HS-5 cocultures. In $2 \mathrm{D}$ and ICC cultures, $\mathrm{hFOB}$ 1.19 and HS-5 co-cultures show similar numbers of $\mathrm{CD} 34^{+} / \mathrm{lin}^{-}$cells. It has been hypothesized that the direct cell-cell contacts at the endosteal surface are important for stem cell maintenance, particularly between HSCs and osteoblasts. ${ }^{[1,7,42]}$ As the osteoblast-HSC interaction is between two transmembrane proteins, Ang-1 and Tie2, ${ }^{[44]}$ it is logical that the cultures with direct cell-cell contact enable these interactions. Thus, when utilizing osteoblasts as a source of signal for $\mathrm{CD} 34^{+} / \mathrm{lin}^{-}$cell maintenance within an in vitro HSC niche, one needs to utilize a matrix that allows for physical contact between cells.

In summary, the ability to organize key aspects of the HSC niche ex vivo will provide a tool for studying pathology and potential cures for many blood and bone marrow diseases, including chronic myelogenous leukemia and bone marrow failure diseases. Critical evaluation of the best method to 
Table 1. Expansion of cells in different matrices.

\begin{tabular}{|c|c|c|c|c|c|}
\hline & & \multicolumn{2}{|c|}{ Total cells } & \multicolumn{2}{|c|}{ CD34 $/$ lin $^{-}$cells } \\
\hline & & Day 7 & Day 14 & Day 7 & Day 14 \\
\hline \multirow[t]{3}{*}{ 2D } & CD34+ alone & 0.419 & 0.025 & 0.138 & 0.008 \\
\hline & hFOB $1.19 /$ CD $34+^{+}$ & 0.994 & 8.567 & 0.237 & 0.848 \\
\hline & $\mathrm{HS}-5 / \mathrm{CD}_{4} 4^{+}$ & 1.019 & 6.229 & 0.378 & 1.050 \\
\hline \multirow[t]{3}{*}{ ICCs } & $\mathrm{CD} 34^{+}$alone & 0.113 & 0.150 & 0.047 & 0.013 \\
\hline & hFOB $1.19 /{\text { CD } 34^{+}}^{+}$ & 1.305 & 0.660 & 0.425 & 0.186 \\
\hline & $\mathrm{HS}-5 / \mathrm{CD} 4^{+}$ & 0.461 & 0.855 & 0.293 & 0.089 \\
\hline \multirow[t]{3}{*}{ Matrigel } & $\mathrm{CD} 34^{+}$alone & 0.304 & 0.431 & 0.015 & 0.014 \\
\hline & hFOB 1.19/ CD34 & 5.591 & 1.789 & 0.024 & 0.052 \\
\hline & HS-5/ CD34 ${ }^{+}$ & 13.502 & 5.408 & 0.112 & 0.504 \\
\hline \multirow[t]{3}{*}{ Puramatrix } & $\mathrm{CD} 34^{+}$alone & 0.023 & 0.023 & 0.001 & 0.002 \\
\hline & hFOB $1.19 / \mathrm{CD}^{2} 4^{+}$ & 0.109 & 0.251 & 0.003 & 0.112 \\
\hline & HS-5/ CD34 ${ }^{+}$ & 0.110 & 0.064 & 0.006 & 0.504 \\
\hline
\end{tabular}

Expansion is calculated by the number of cells extracted divided by the number of cells added to the matrix at the beginning of culture (total cells or CD34 ${ }^{+} /$lin $^{-}$cells).

recreate the HSCs using stromal cells and different types of $3 \mathrm{D}$ matrix is much needed to establish a pathway toward adequate patient-specific ex-vivo bone marrow analogs. 2D well plate cultures demonstrated the greatest expansion of $\mathrm{CD}^{4} 4^{+} / \mathrm{lin}^{-}$cells. These cultures provided both direct cell-cell contacts and soluble cytokine communication. ICC scaffolds, $3 \mathrm{D}$ cultures that permitted both direct HSC-stromal cell con-

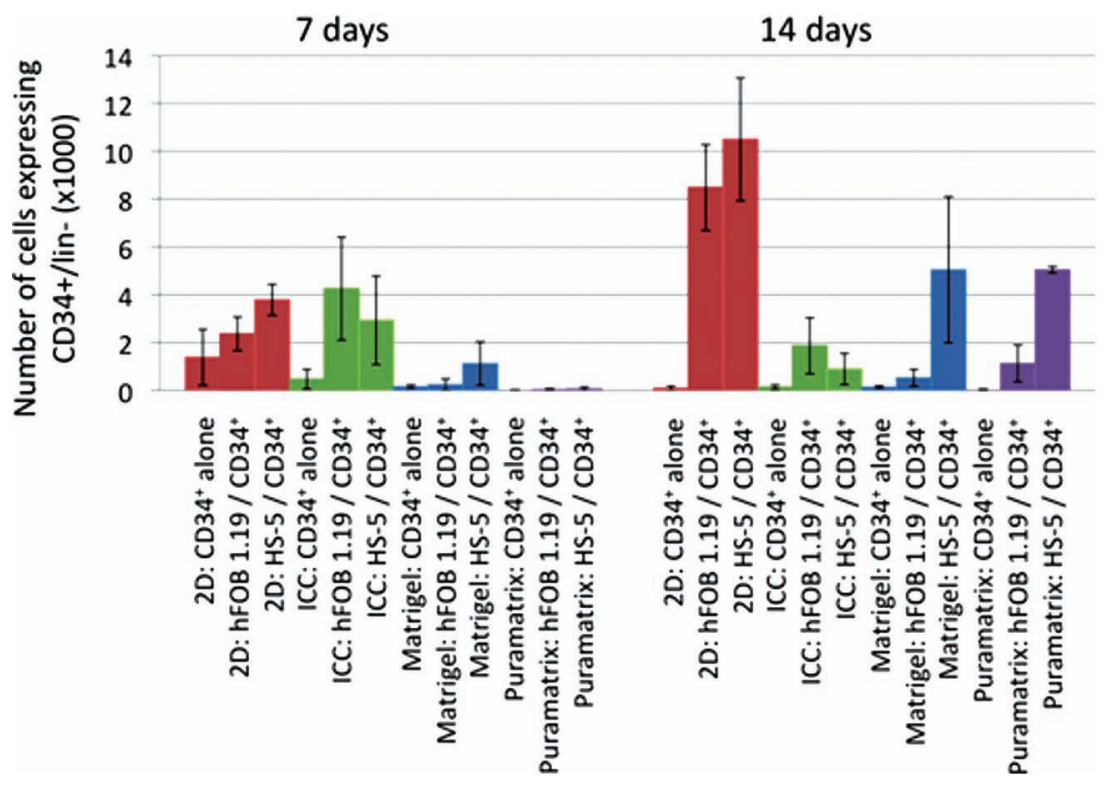

Figure 3. Number of $\mathrm{CD}_{3} 4^{+} / \mathrm{lin}^{-}$cells extracted. For all matrices and times, co-cultures produced significantly $(\mathrm{p}<0.05)$ more $\mathrm{CD} 34^{+} / \mathrm{lin}^{-}$cells than $\mathrm{CD} 34^{+}$cells grown alone. When comparing co-cultures within culture formats, at seven days, hFOB $1.19 / \mathrm{CD} 34^{+}$cultures in $2 \mathrm{D}$ produced significantly more $(\mathrm{p}<0.05) \mathrm{CD}_{4} 4^{+}$/lin cells than did $\mathrm{HS}-5 / \mathrm{CD} 34^{+}$cultures in $2 \mathrm{D}$ and at 14 days, for hFOB $1.19 / \mathrm{CD} 34^{+}$cultures in Matrigel and Puramatrix produced significantly more $\mathrm{CD} 34^{+} / \mathrm{lin}^{-}$cells than did $\mathrm{HS}-5 / \mathrm{CD} 34^{+}$cultures in these formats. Comparing culture formats, 2D and ICC co-cultures produced significantly more $\mathrm{CD}_{3} 4^{+} / \mathrm{lin}^{-}$cells than Matrigel and Puramatrix at seven days, and at 14 days 2D cultures produced more $\mathrm{CD}_{3} 4^{+}$/ lin- cells than all 3D matrices. tacts and the release of soluble cytokines, caused quiescence of the $\mathrm{CD} 34^{+} / \mathrm{lin}^{-}$cells, much like what is seen in in vivo bone marrow. Matrigel cell cultures encapsulating the cells into ECM-type of environment inhibited cell-cell contacts but allowed for communication through soluble cytokines. They exhibited a great population of differentiated cells that did not have the $\mathrm{CD} 34^{+} / \mathrm{lin}^{-}$phenotype. This fact should be attributed to the exogenous growth factors contained in the matrix. Puramatrix showed a number of $\mathrm{CD} 34^{+} / \mathrm{lin}^{-}$cells similar to Matrigel after 14 days.

As the quiescent cancer stem cells are not affected by typical chemotherapy drugs, the ability to keep HSCs quiescent in culture is essential for modeling both healthy and diseased marrow. Considering an in-vitro HSC niche for the testing of drugs, one should utilize a 3D culture format that provides direct cell-cell contacts, which is essential in designing an ex vivo HSC niche. In addition to the dimensionality of cell-cell contacts and soluble cytokine gradients, one must also remember that in $3 \mathrm{D}$ cultures, the gradients of drugs, as well as the ability of HSCs protected by stromal cells, are much closer to in vivo condition.

Further work needs to be done to elucidate the necessary cell types that cause HSCs to behave as they do in vivo. Once this is achieved, the model should also be examined by utilizing diseased HSCs, to ensure that the model can be used as a disease model. This will give clues to the pathophysiology of many blood and bone marrow diseases. 
A

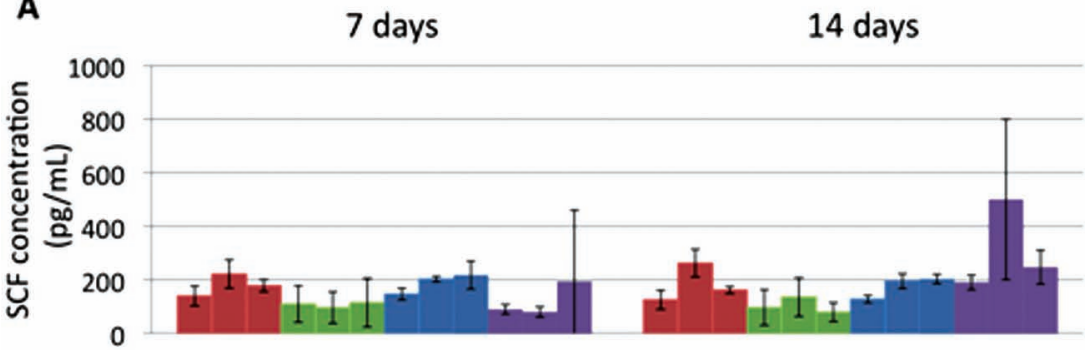

B

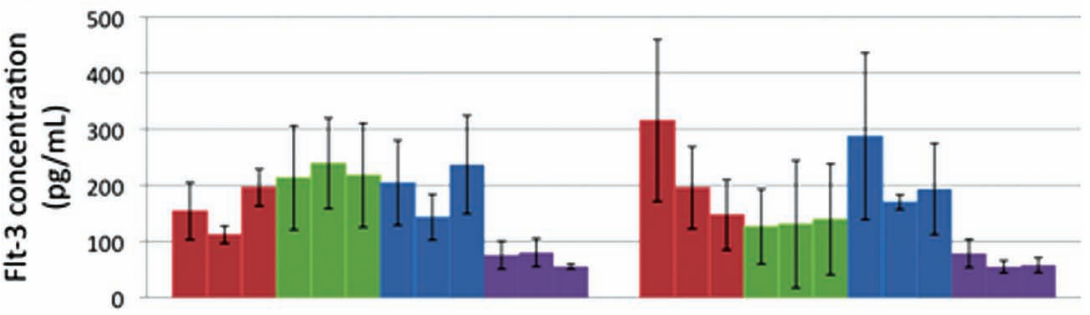

C
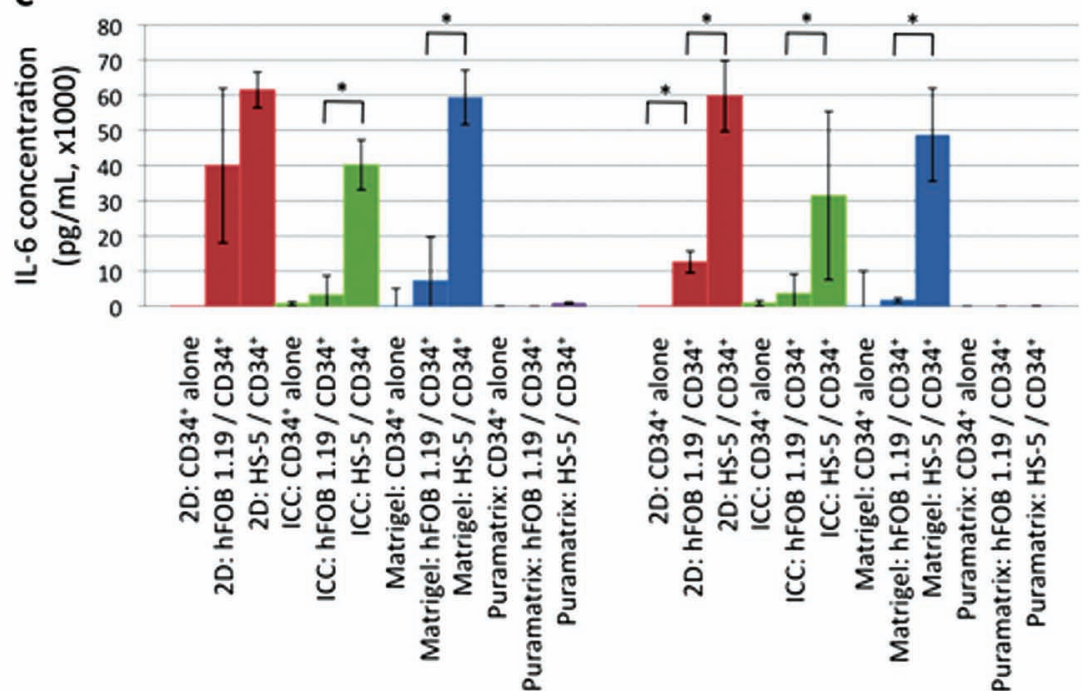

Figure 4. Concentrations of relevant cytokines in the media as determined by ELISAs. (A) SCF (B) Flt-3, (C) IL-6. Starred values represent values that are statistically significant $(p<0.05)$ when compared to the other stromal cell in that culture format (i.e., 2D, Matrigel, or ICC) for that day $(n=4-6)$. Note that although difficult to visualize on the Figure $4 \mathrm{C}$, the average concentration of IL- 6 for CD34+ cells grown alone, with hFOB 1.19 cells, and with HS- 5 cells, respectively, in Puramatrix are as follows. 7 days $(\mathrm{pg} / \mathrm{mL}): 83.7 \pm 57.7,26.3 \pm 11.3$, and $927.9 \pm 192.5 .14$ days $(\mathrm{pg} / \mathrm{mL}): 47.0 \pm 19.5,31.0 \pm 11.5$, and $135.3 \pm 37.7$.

sium persulfate (KPS, Sigma) $(0.1 \mathrm{~g})$ to deoxygenated water $(10 \mathrm{~mL})$. Next, an acrylamide precursor solution was made by adding $\mathrm{N}, \mathrm{N}$ dimethylacrylamide (DMAA, Aldrich) (3.5 g), (3-Acrylamidopropyl)trimehtylammonium chloride (AMTAC, Aldrich) (0.5 g) and $\mathrm{N}, \mathrm{N}$ methylenebis(acrylamide) (MBA, Aldrich) $(0.05 \mathrm{~g})$ to deoxygenated water $(9 \mathrm{~mL})$. Colloidal crystals were added to vials, and enough precursor solution was added to completely submerge the crystals. The colloidal crystals were then centrifuged in precursor solution for $25 \mathrm{~min}$ at 5500 RPM. Next, initiator $(300 \mu \mathrm{L})$ was added to each vial, and centrifugation was repeated for an additional $15 \mathrm{~min}$. Vials were heated in an oven for $3 \mathrm{~h}$ at $75^{\circ} \mathrm{C}$ with the caps placed on the vials but not screwed tight, and then overnight at $60{ }^{\circ} \mathrm{C}$ with caps screwed tight. Gels were then cracked out of vials, and excess gel was scraped off of the colloidal crystals using a razor blade.

Glass beads were removed as described previously using a series of hydrofluoric acid and hydrochloric acid washes; removal of soda lime was accelerated by ultrasonicating during acid washes. The resultant $1 \mathrm{~cm} \mathrm{ICCs}$ were washed several times in phosphate buffered saline (PBS) before cutting. To cut the $1 \mathrm{~cm} \mathrm{ICCS}$ into thin scaffolds, ICCS were first mounted in HistoGel (Thermo Scientific), and cut into $350 \mu \mathrm{m}$ thick sections using a Vibratome 3000 series sectioning system (VIbratome, St. Louis, MO). Thin ICCS were then washed sequentially with $\mathrm{PBS}, \mathrm{pH}$ 10 buffer, calcium chloride, and PBS. Scaffolds were sterilized by washing in 190 proof ethanol, and then were washed twice in sterile PBS.

Stromal Cell Expansion: Human fetal osteoblast (hFOB) cell line 1.19 (CRL-11372) and human bone marrow stromal (HS-5) cells (CRL-11882) were purchased from American Tissue Culture Corporation (ATCC, Manassas, VA) hFOB 1.19 cells were grown as recommended by ATCC in 45\% Ham's F12 medium,

\section{Experimental Section}

ICC Fabrication: Colloidal crystals were prepared in a manner similar to those previously described. ${ }^{[43]}$ One gram of soda lime beads with a diameter of $80 \mu \mathrm{m}$ (Thermo Scientific) were mixed with ethylene glycol (approximately $5 \mathrm{~mL}$ ). Under constant sonication, one drop of beads was added every 20 min to the top of the pipette that was inserted into a $4.5 \mathrm{~mm}$ diameter vial. Drops were added until the height of beads in the vial was approximately $1 \mathrm{~cm}$. Ethylene glycol was evaporated in a furnace at $165^{\circ} \mathrm{C}$ overnight, and beads were annealed at $665^{\circ} \mathrm{C}$ for $3 \mathrm{~h}$. Annealed colloidal crystals were cracked out of the vials.

Cationic hydrogels were infiltrated and formed in the colloidal crystals as follows. An initiator solution was made by adding potas-
45\% Dulbecco's modified Eagle's Medium (DMEM), and 10\% fetal bovine serum (FBS) (Gibco, Frederick, MD) supplemented with G418 $(0.3 \mathrm{mg} / \mathrm{mL})$. HS- 5 cells were grown as recommended by ATCC in DMEM supplemented by $10 \%$ FBS and $1 \%$ penicillin-streptomycin. Both cell types were grown at $37{ }^{\circ} \mathrm{C}$ and $5 \%$ carbon dioxide $\left(\mathrm{CO}_{2}\right)$, with the medium changed every 2 to 3 days.

Stromal and CD34+ Seeding in 2D Cultures: For each matrix type, hFOB 1.19 or HS-5 cells were seeded at a density of 40000 cells per culture. This number was chosen to avoid contact inhibition in 2D 96-well plate cultures. Stromal cells were seeded directly onto the plate, and allowed to attach for three hours before irradiating at 6000 rads with $\gamma$-rays. Media was then changed to StemSpan (StemCell Technologies, Vancouver, BC) supplemented with $40 \mu \mathrm{g} / \mathrm{mL}$ low density lipoprotein (Sigma) 
and $1 \%$ penicillin-streptomycin. Frozen bone marrow $\mathrm{CD} 34^{+}$cells (StemCell Technologies) were thawed and washed with StemSpan as directed by the cell supplier. $\mathrm{CD} 34^{+}$cells were added to cell cultures at a density of 10000 cells/well and cultured at $37^{\circ} \mathrm{C}$ and $5 \% \mathrm{CO}_{2}$. Controls were prepared by culturing $\mathrm{CD}_{3} 4^{+}$cells without stromal cells in 96-well plates.

Stromal and CD34+ Seeding in Matrigel Cultures: In order to co-culture stromal cells with CD34+ cells in Matrigel, hFOB 1.19 and HS- 5 cells were $\gamma$-irradiated at 6000 rads in $75 \mathrm{~cm}^{2}$ flasks prior to seeding in gels. Matrigel cultures were prepared according to manufacturer's instructions for culturing cells within the matrix. Briefly, three tubes were placed on ice and equal volumes of Matrigel was pipetted into each tube. hFOB 1.19 or HS-5 cells were counted and placed into Matrigel tubes so that each well would receive 40000 stromal cells; the third tube was left without cells. $\mathrm{CD} 34^{+}$cells were thawed and washed with StemSpan, and $\mathrm{CD} 34^{+}$ cells were added to cell cultures at a density so that $10000 \mathrm{CD}_{3} 4^{+}$ cells would be included in each well. Matrigel, stromal cells, and $\mathrm{CD} 34^{+}$cells were gently mixed by pipetting, and $32 \mu \mathrm{L}$ of Matrigelcell mixtures were added to each well. Cells were cultured at $37^{\circ} \mathrm{C}$ and $5 \% \mathrm{CO}_{2}$.

Stromal and CD34+ Seeding in Puramatrix Cultures: As with Matrigel cultures, hFOB 1.19 and HS-5 cells were irradiated at 6000 rads in $75 \mathrm{~cm}^{2}$ flasks prior to seeding in Puramatrix gels. Puramatrix cultures were prepared according to manufacturer's instructions for encapsulating cells. Briefly, Puramatrix $(25 \mu \mathrm{L})$ was added to each well with an equal volume of cell suspension. Cell suspensions were prepared in concentrations described for Matrigel cultures, except cells were suspended in $10 \%$ sucrose solution instead of media. Suspensions were mixed with Puramatrix directly in the well plate, and cultures were allowed to set for 5 minutes before StemSpan media was layed on top. Media was changed twice over the next hour. Cells were cultured at $37^{\circ} \mathrm{C}$ and $5 \% \mathrm{CO}_{2}$.

Cell Seeding in ICC Scaffolds: One scaffold was placed in a well of a 96-well plate. $100 \mu \mathrm{L}$ of 190 proof ethanol was added to each well. Scaffolds were allowed to equilibrate for $10 \mathrm{~min}$ before ethanol was removed and replaced with an additional fresh ethanol $(100 \mu \mathrm{L})$. After $10 \mathrm{~min}$, most of the ethanol was removed and plates were placed in an incubator at $37{ }^{\circ} \mathrm{C}$ overnight to evaporate any residual ethanol. The next day, cell solutions of either hFOB 1.19 or HS-5 cells were made at a density of 40000 cells per $20 \mu \mathrm{L}$. $20 \mu \mathrm{L}$ of cell suspension gently was pipetted directly onto each dehydrated scaffold, and well plates were placed in an incubator for three hours. Wells were then filled halfway with HS-5 media (described above), and cells and scaffolds were irradiated at 6000 rads. Media was then removed and replaced with StemSpan media. CD34 ${ }^{+}$cells were thawed and washed with StemSpan as described above. $\mathrm{CD} 34^{+}$cells were added to cell cultures at a density of 10,000 cells/well and cultured at $37{ }^{\circ} \mathrm{C}$ and $5 \% \mathrm{CO}_{2}$. Controls were prepared by culturing $\mathrm{CD}_{3} 4^{+}$cells without stromal cells in ICC scaffolds.

Live/Dead Staining: After 8 days of culture, cells were incubated in calcein $\mathrm{AM}(2 \mathrm{mM})$ and ethidium homodimer-1 (4 mM) using a Live/Dead Viability/Cytotoxicity Kit (Invitrogen Corporation, Carlsbad, CA). Images were acquired directly in 96-well plates using a Leica DM IRB inverted microscope.

Flow Cytometric Analysis: Enumeration of cells expressing the $\mathrm{CD}_{34} 4^{+}$marker was performed by flow cytometry. For $2 \mathrm{D}$ and
ICC cultures, cells were released through treatment with trypsinethylenediaminetetraacetic acid and repeated pipetting. Matrigel cultures were released by treatment with Dispase and repeated pipetting. Cells were washed in ice cold $2 \%$ FBS in PBS, and incubated with fluorescently labeled CD34, glycophorin A (GpA), and lineage cocktail 1 (lin1) (CD3, CD14, CD16, CD19, CD20, CD56) antibodies (BD Biosciences, San Jose, CA). The combination of lin1 and $\mathrm{GpA}$ are hereafter referred to as lin. Relevant single color, negative, and isotype controls were prepared for compensation and to distinguish specific binding. Flow cytometry was performed on either a Beckman Coulter Quanta SC or a BD FCSCanto II. Regions positive for CD34 and lin1/GpA were determined based on isotype controls.

Enzyme-Linked Immunosorbent Assays (ELISAs): ELISAs for interleukin 6 (IL-6) (R\&D Systems, Minneapolis, MN), stem cell factor (SCF) (R\&D Systems), and fms-like tyrosine kinase receptor-3 (Flt3) (R\&D Systems) were performed according to manufacturer instructions.

[1] G. B. Adams, D. T. Scadden, Nat. Immunol. 2006, 7, 333-337.

[2] A. Wilson, A. Trumpp, Nat. Rev. Immunol. 2006, 6, 93-106.

[3] S. K. Nilsson, H. M. Johnston, G. A. Whitty, B. Williams, R. J. Webb, D. T. Denhardt, I. Bertoncello, L. J. Bendall, P. J. Simmons, D. N. Haylock, Blood 2005, 106, 1232-1239.

[4] M. C. Puri, A. Bernstein, Proc. Natl. Acad. Sci. USA 2003, 100, $12753-12758$.

[5] J. Larsson, M. Ohishi, B. Garrison, M. Aspling, V. Janzen, G. B. Adams, M. Curto, A. I. McClatchey, E. Schipani, D. T. Scadden, Cell Stem Cell 2008, 3, 221-227.

[6] M. J. Kiel, O. H. Yilmaz, T. Iwashita, O. H. Yilmaz, C. Terhorst, S. J. Morrison, Cell 2005, 121, 1109-1121.

[7] L. M. Calvi, G. B. Adams, K. W. Weibrecht, J. M. Weber, D. P. Olson, M. C. Knight, R. P. Martin, E. Schipani, P. Divieti, F. R. Bringhurst, L. A. Milner, H. M. Kronenberg, D. T. Scadden, Nature 2003, 425, 841-846.

[8] S. M. Graham, H. G. Jørgensen, E. Allan, C. Pearson, M. J. Alcorn, L. Richmond, T. L. Holyoake, Blood 2002, 99, 319-325.

[9] T. Holyoake, X. Jiang, C. Eaves, A. Eaves, Blood 1999, 94, 2056-2064.

[10] S. M. Garrido, F. R. Appelbaum, C. L. Willman, D. E. Banker, Exp. Hematol. 2001, 29, 448-457.

[11] B. A. Roecklein, B. Torok-Storb, Blood 1995, 85, 997-1005.

[12] B. A. Roecklein, J. Reems, S. Rowley, B. Torok-Storb, Biol. Blood Marrow Transplant. 1998, 4, 61-68.

[13] P. W. Zandstra, E. Conneally, A. L. Petzer, J. M. Piret, C. J. Eaves, Proc. Natl. Acad. Sci. USA 1997, 94, 4698-4703.

[14] C. Rofani, L. Luchetti, G. Testa, R. Lasorella, G. Isacchi, G. F. Bottazzo, A. C. Berardi, Stem Cells Dev. 2009, 18, 671-682.

[15] P. Laneuville, C. Dilea, O. Q. P. Yin, R. C. Woodman, J. Mestan, P. W. Manley, J. Clin. Oncology 2010, 28, 169.

[16] C. H. Cho, J. F. Eliason, H. W. T. Matthew, J. Biomed. Mater. Res. A 2008, 86, 98-107.

[17] A. P. D. N. de Barros, C. M. Takiya, L. R. Garzoni, M. L. Leal-Ferreira, H. S. Dutra, L. B. Chiarini, M. N. Meirelles, R. Borojevic, D. M. I. Rossi, PLoS ONE 2010, 5, e9093.

[18] K.-N. Chuaa, C. Chaib, P.-C. Leeb, S. Ramakrishnaa, K. W. Leongb, H. Q. Mao, Exp. Hematol. 2008, 35, 771-781.

[19] K. Ma, C. K. Chan, S. Liao, W. Y. K. Hwang, Q. Feng, S. Ramakrishna, Biomaterials 2008, 29, 2096-2103

[20] Y. Li, T. Ma, D. A. Kniss, S. T. Yang, L. C. Lasky, J. Hematother. Stem Cell Res. 2001, 10, 355-368.

[21] Q. Feng, C. Chai, X.-S. Jiang, K. W. Leong, H.-Q. Mao, J. Biomed. Mater. Res. A 2006, 78, 781-791. 
[22] I. Leisten, R. Kramann, M. S. Ventura Ferreira, M. Bovi, S. Neuss, P. Ziegler, W. Wagner, R. Knüchel, R. K. Schneider, Biomaterials 2012, 33, 1736-1747.

[23] M. M. Cook, K. Futrega, M. Osiecki, M. Kabiri, B. Kul, A. Rice, K. Atkinson, G. Brooke, M. Doran, Tissue Eng. Part C Methods 2012, 18, 319-328.

[24] B. Heissig, K. Hattori, S. Dias, M. Friedrich, B. Ferris, N. R. Hackett, R. G. Crystal, P. Besmer, D. Lyden, M. A. Moore, Z. Werb, S. Rafii, Cell 2002, 109, 625-637.

[25] K. Chadwick, L. Wang, L. Li, P. Menendez, B. Murdoch, A. Rouleau, M. Bhatia, Blood 2003, 102, 906-915.

[26] G. Benton, J. George, H. Kleinman, I. Arnaoutova, J. Cell. Physiol. 2009, 221, 18-25.

[27] K. Hotary, E. Allen, P. Brooks, N. Datta, M. Long, S. Weiss, Cell 2003, 114, 33-45.

[28] G. Y. Lee, P. A. Kenny, E. H. Lee, M. J. Bissell, Nat. Methods 2007 , 4, 359-365.

[29] M. Zegers, O’L. Brien, W. Yu, A. Datta, K. Mostov, Trends Cell Biol. 2003, 13, 169-176.

[30] A. Rizki, V. M. Weaver, S.-Y. Lee, G. I. Rozenberg, K. Chin, C. A. Myers, J. L. Bascom, J. D. Mott, J. R. Semeiks, L. R. Grate, I. S. Mian, A. D. Borowsky, R. A. Jensen, M. O. Idowu, F. Chen, D. J. Chen, O. W. Petersen, J. W. Gray, M. J. Bissell, Cancer Res 2008, 68, 1378-1387.

[31] Z. Tang, G. Geng, Q. Huang, G. Xu, H. Hu, J. Chen, J. Li, J. Surgical Res. 2009, 167, 62.

[32] J. Kisiday, M. Jin, B. Kurz, H. Hung, C. Semino, S. Zhang, A. J. Grodzinsky, Proc. Natl. Acad. Sci. USA 2002, 99, 9996.

[33] S. Zhang, T. Holmes, C. DiPersio, R. Hynes, X. Su, A. Rich, Biomaterials 1995, 16, 1385-1393.

[34] J. E. Nichols, J. Cortiella, J. Lee, J. A. Niles, M. Cuddihy, S. Wang, J. Bielitzki, A. Cantu, R. Mlcak, E. Valdivia, R. Yancy, M. L. McClure, N. A. Kotov, Biomaterials 2009, 30, 1071-1079.
[35] N. A. Kotov, Y. Liu, S. Wang, C. Cumming, M. Eghtedari, G. Vargas, M. Motamedi, J. Nichols, J. Cortiella, Langmuir 2004, 20, 7887-7892.

[36] J. Lee, M. Cuddihy, G. M. Cater, N. A. Kotov, Biomaterials 2009, 30, 4687-4694.

[37] J. Lee, G. D. Lilly, R. C. Doty, P. Podsiadlo, N. A. Kotov, Small 2009, 5, 1213.

[38] J. Lee, S. Shanbhag, N. Kotov, J. Mater. Chem. 2006, 16, 3558.

[39] J. Lee, N. A. Kotov, Small 2009, 5, 1008-1013.

[40] J. Lee, M. J. Cuddihy, N. A. Kotov, Tissue Engin. B 2008, 14, 61-86.

[41] Y. Liu, S. Wang, J. Lee, N. Kotov, Chem. Mater. 2005, 17, 4918.

[42] Y. Zhang, S. Wang, M. Eghtedari, M. Motamedi, N. Kotov, Adv. Funct. Mater. 2005, 15, 725-731.

[43] M. J. Cuddihy, N. A. Kotov, Tissue Engin. A 2008, 14, 1639-1649.

[44] F. Arai, A. Hirao, M. Ohmura, H. Sato, S. Matsuoka, K. Takubo, K. Ito, G. Y. Koh, T. Suda, Cell 2004, 118, 149-161.

[45] M. Savona, M. Talpaz, Nat. Rev. Cancer 2008, 8, 341-350.

[46] H. E. Fleming, V. Janzen, C. Lo Celso, J. Guo, K. M. Leahy, H. M. Kronenberg, D. T. Scadden, Cell Stem Cell 2008, 2, 274-283.

[47] G. B. Adams, K. T. Chabner, I. R. Alley, D. P. Olson, Z. M. Szczepiorkowski, M. C. Poznansky, C. H. Kos, M. R. Pollak, E. M. Brown, D. T. Scadden, Nature 2006, 439, 599-603.

[48] S. A. Harris, R. J. Enger, B. L. Riggs, T. C. Spelsberg, J. Bone Miner. Res. 1995, 10, 178-186.

[49] A. H. Beddoe, Phys. Med. Biol. 1977, 22, 298-308.

[50] A. H. Beddoe, Calcif. Tissue Res. 1978, 25, 273-281.

[51] A. H. Beddoe, P. J. Darley, F. W. Spiers, Phys. Med. Biol. 1976, 21, 589-607.

Received: August 30, 2012

Published online: December 21, 2012 